\title{
K.H. LANRE SAID : ULAMA PENDIDIK DARI DI/TII HINGGA ERA REFORMASI
}

\section{K.H. Lanre Said: Great Educator from DI/TII to Reformation Era}

\author{
Ilham Kadir \\ Sekolah Tinggi Keguruan dan Ilmu Pendidikan (STKIP) Muhammadiyah \\ Enrekang, Indonesia \\ Email : ilhamkadir231111@gmai.com
}

\section{Keywords : \\ scholar, bugis, K..H. Lanre Said, \\ Darul Huffadh, Tuju-Tuju}

\begin{abstract}
This study aims to reveal the various aspects of life of K.H. Lanre Said, a great scholar, great educator whose services are so great in fostering generations through the educational institutions he founded, namely Darul Huffadh Islamic Boarding School located in Tuju-Tuju Kajuara Bone, South Sulawesi. This research is a type of qualitative descriptive research with a historical approach. Data collection techniques used are interviews, document studies, literature studies, and field observations. The results of this study reveal various aspects of life and the path of da'wah and the messages of K.H. Lanre Said, as an educating scholar, and the perfect hafizh of al-Qur'an. He is a Bugis cleric who can be used as an example from various sides, from the scientific aspect, the power of memorization, to being a role model in life. K.H. Lanre Said became a real example of a Bugis ulama, spending his age in the midst of society by establishing educational institutions to educate the life of the nation, living simply as it is, and the messages are always actual to practice. K.H. Lanre Said's main capital in affirming itself as a guiding ulama to the right path is the depth of knowledge, real practice, good behavior (ampe-ampe madeceng), avoiding the word lies even if only joking, prioritizing public rather than personal interests, and always willing and sincere in doing. With this power, the position of K.H. Lanre Said in the middle of the Bone community in general and the Tuju-Tuju community in particular is irreplaceable.
\end{abstract}

\section{ABSTRAK}

Penelitian ini bertujuan untuk mengungkap berbagai sisi kehidupan K.H. Lanre Said, seorang alim besar, pendidik agung yang jasa-jasannya begitu besar dalam membina generasi lewat lembaga pendidikan yang ia dirikan yakni Pondok Pesantren Darul Huffadh yang berlokasi di Tuju-Tuju Kajuara Bone Sulawesi Selatan. Penelitian ini merupakan jenis penelitian diskriptif kualitatif dengan pendekatan sejarah. Teknik pengumpulan data yang digunakan adalah wawancara, studi dokumen, kajian pustaka, dan observasi lapangan. Hasil penelitian ini mengungkap berbagai sisi kehidupan dan jalan dakwah serta pesan-pesan K.H. Lanre Said, sebagai seorang ulama pendidik, dan hafizh alQur'an yang sempurna. Ia adalah seorang ulama Bugis yang dapat dijadikan contoh dari berbagai sisi, mulai dari aspek keilmuan, kekuatan hafalan, hingga menjadi panutan dalam hidup. K.H. Lanre Said menjadi contoh nyata seorang ulama Bugis, menghabiskan umurnya di tengah masyarakat dengan mendirikan lembaga pendidikan untuk mencerdaskan kehidupan bangsa, hidup sederhana apa adanya, dan pesan-pesannya selalu aktual untuk diamalkan. Modal utama K.H. Lanre Said dalam meneguhkan dirinya sebagai ulama penuntun ke jalan yang benar adalah kedalaman ilmu, pengamalan yang nyata, adab yang baik (ampe-ampe madeceng), menghindari kata dusta walau hanya bercanda, mengutamakan kepentingan umum daripada pribadi, dan selalu rela dan iK.H.las dalam berbuat. Dengan kekuatan tersebut sehingga posisi K.H. Lanre Said di tengah masyarakat Bone secara umum dan masyarakat Tuju-Tuju secara Khusustidak tergantikan.

\footnotetext{
Riwayat artikel : Diterima : 16 Desember 2019; Direvisi : Desember 2019; Disetujui : Desember 2019; Tersedia online : 27 Desember 2019

How to cite : Kadir, I. (2019). K.H. Lanre Said : Ulama Pendidik dari DI/TII hingga Reformasi. NUKHBATUL 'ULUM : Jurnal Bidang Kajian Islam, 5(2), 125-144. https://doi.org/10.36701/nukhbah.v5i2.87
} 


\section{PENDAHULUAN}

Sejak masuknya Islam di Indonesia hingga saat ini, ulama sebagai pemimpin ummat telah menjadi sorotan dalam kajian-kajian para peneliti terhadap kepemimpinan Islam. Umumnya, para peneliti dalam pelbagai kajian dan penelitian mereka tentang ulama di Indonesia melahirkan konklusi bahwa ulama memiliki posisi strategis dan sentral dalam masyarakat. Clifford Geertz sebagaimana dikutip As'ad berpendapat bahwa ulama sebagai makelar budaya (cultural brokers) yang berfungsi sebagai mata rantai utama yang menghubungkan sistem lokal dengan keseluruhan sistem yang lebih besar. Para ulama telah memainkan peran perantara bagi ummat Islam dengan memberi mereka pemahaman tentang apa yang sedang terjadi pada dunia luar (As'ad, 2011: 1).

\section{Masyarakat Bugis umumnya menganggap bahwa puncak dari keberhasilan seorang pelajar adalah mampu menjadi seorang panrita atau ulama. S \\ truktur sosial masyarakat Bugis yang melekat sejak zaman dahulu adalah adanya klasifikasi strata sosial sebagaimana berikut, (1) to manurung (para raja yang diyakini berasal dari dunia luar); (2) to panrita (ulama); (3) to acca (cendekiawan); (4) to sugi (orang kaya); (5) to warani (jawara); (6) to maradeka (orang merdeka); dan (7) ata (hamba), (Palimai, 2010: 32).}

Panrita dan To Acca, adalah hasil dari proses pendidikan yang dapat dinikmati oleh semua orang. Secara

${ }^{1}$ https://id.wikipedia.org/wiki/Anregurutta bahasa "Panrita" berasal dari "ita" yang berarti "melihat" penambahan kata "pan" pada awal kata menjadikan maknanya berubah menjadi pelaku, jadi "pan-rita" dapat diartikan "yang dapat melihat" namun melihat disini adalah dapat mengetahui pada hal-hal yang bersifat gaib dengan izin Allah ${ }^{1}$.

Secara umum dan yang dimaksud dalam struktur sosial di atas, yang dapat disebut Panrita hanyalah yang bergelar ulama dan dapat memberikan pelarajan agama kepada para guru dan orang awam. Seorang Panrita adalah yang mampu memiliki keluasan ilmu, sekaligus dapat menjadi suri teladan bagi K.H.alayak ramai. Untuk itulah panrita biasa juga disebut to malebbi atau orang mulia. Mulia karena ilmu dan adabnya. Adab dalam istilah Bugis Bone adalah ampe-ampe madeceng (akhlak mulia) $)^{2}$.

Namun demikian, istilah kiai sebagaimana dipergunakan oleh masyarakat Jawa juga dipakai untuk menyebut golongan ulama, atau pimpinan pesantren dan mengajar kitab-kitab klasik kepada para santrinya, dalam penelitian ini kata 'kiai' juga digunakan untuk menunjukkan kata ganti ulama, anregurutta, dan gururtta. Hanya saja, penggunaan istilah kiai dalam masyarakat Bugis bersifat umum untuk semua ahli agama, sementara istilah anregurutta selain menunjukkan kompetensi yang dimiliki juga merujuk pada prilaku kesehariannya (ampe-ampe madeceng) yang melambangkan dan menunjukkan Kharisma dan kewibawaannya di tengah masyarakat, karena itulah,

2 https://www.academia.edu/37618597/Gurutta_Anreg uru_Panrita 
menurut Ahmad, anregurutta atau gurutta memang lebih spesifik untuk ulama Bugis. Dilihat dari sudut kompetensi, memang ulama Bugis, setidaknya merujuk pada tiga kompetensi dasar, meliputi, penguasaan ilmu agama, pengamalan agama, dan akhlak kepribadian (Ahmad, 2008: 416), jika diterjemhakan secara sederhana anregurutta bermakna "syaikhuna" atau "mahaguru kita".

Kompetensi keilmuan ulama Bugis sebenarnya tidak jauh beda dengan standar ulama mujtahid, seperti penguasaan terhadap al-Qur'an dan sunnah dan segenap ilmu-ilmu alat dalam bahasa Arab, dan ilmu-ilmu pendukung lainnya sebagai syarat menjadi mujtahid. Syarat-syarat menjadi ulama mujtahid, selain hafalan al-Qur'an dan jumlah tertentu dari hadits, serta penguasaan ilmu masuk dalam kategori ilmu duabelas. Selain itu, ada beberapa tambahan Khusus sebagai ulama yang berdakwah di tengah masyarakat Bugis maka harus memahami bahasa kaumnya. Maka, kompetensi keilmuannya harus juga didukung dengan ilmu-ilmu alat berhubungan dengan suku Bugis, seperti mampu membaca dan menulis huruf lontara atau aksara Bugis, mampu berbicara dan memberi ceramah, pengajian, dan sejenisnya dalam bahasa Bugis, walaupun tidak mesti berasal dari suku Bugis, yang jelas jika kompetensi tambahan dan persifat Khusus tersebut dapat dipenuhi maka sudah masuk dalam kategori 'Ulama Bugis'.

Kompetensi berikutnya adalah bersifat aplikatif, atau kompetensi sosial yang membutuhkan skil. Di sini masyarakat akan menilai sejauhmana seorang ulama Bugis mampu mengamalkan ilmu yang dimilikinya, terutama untuk diri, keluarga, dan ummat secara keseluruhan. Setinggi apa pun ilmu seseorang tapi tanpa diiringi pengamalan maka tidak akan dianggap sebagai ulama Bugis sebab tidak mampu menebar manfaat pada sesamanya. Manusia dalam kategori ini, cocoknya tinggal jauh dari keramaian, kerjanya hanya ibadah dan ibadah, jangan banyak interaksi kepada manusia, sebab makin banyak bertemu dengan manusia potensi dosanya makin banyak pula, dan pada puncaknya yang mampu melakukan kehidupan seperti ini hanyalah para golongan dan aliran sufi zuhud yang benar-benar memandang dunia sebagai bangkai. Namun, menjadi ulama kompetensi mutlak adalah mengamalkan ilmunya, bermanfaat bagi diri dan kaumnya serta taro ada taro gau, apa yang dikatakan itulah yang diperbuat.

Kompetensi terakhir adalah kepribadian yang disebut adab dan akhlak. Inilah inti dari kedua kompetensi sebelumnya. Tingginya ilmu dan amal, harus disempurnakan dengan adab, sebab tujuan pendidikan hakikatnya adalah membentuk manusia beradab, hanya mereka yang beradab akan mampu menjadi orang shaleh. Khusus untuk ulama Bugis, adab dibahasakan dengan ampe-ampe madeceng, atau prilaku yang elok. Suri teladan dari adab adalah bersumber dari golongan yang berilmu, Khususnya para ulama sebagai sumber ilmu dan pengganti peran para nabi.

Salah seorang ulama Bugis yang sangat layak diangkat sejarah hidup dan perjuangannya adalah Anregurutta Haji 
Lanre Said. Dia adalah salah satu murid Syekh Muhammad As'ad Al-Bugisi (1907-1952) dan sekaligus lulusan Madrasah Arabiyah Islamiyah Sengkang. Jika dibandingkan dengan ulama-ulama yang pernah belajar besama-sama di zamannya, Lanre Said adalah yang paling sedikit mendapat porsi publikasi ilmiah. Di antara koleganya yang sudah lebih dulu diangkat adalah, Abdurrahman Ambo Dalle, Daud Ismail, Yunus Martang, Muin Yusuf, Marzuki Hasan, hingga Hamzah Manguluang.

Mengangkat kembali biografi ulama yang pernah berkiprah tanpa pamrih di tengah masyarakat sangat penting, selain sebagai tanda terima kasih dan penghargaan atas jasa-jasa dan pengabdiannya juga sebagai jalan untuk memperkaya Khazanah budaya dan keagamaan sebagai salah satu media komunikasi berkelanjutan dengannya dan merupakan salah satu bentuk pendidikan masyarakat agar supaya menjadikannya patron moral dan adab dalam kehidupan pada pelbagai sisi, termasuk di dalamnya penyusunan biografi merupakan bagian dari Khazanah keagamaan yang mendapatkan perhatian dari para peneliti dan lembaga peneliti (As'ad, 2016: 281).

Oleh karena itu, penelitian ini bertujuan untuk mengungkap berbagai sisi kehidupan K.H. Lanre Said, seorang alim besar, pendidik agung yang jasa-jasannya begitu besar dalam membina generasi lewat lembaga pendidikan yang ia dirikan yakni Pondok Pesantren Darul Huffadh yang

http://www.ilhamkadir.com/2013/02/guruttaanreguru-panrita.html berlokasi di Tuju-Tuju Kajuara Bone Sulawesi Selatan.

Etnis Bugis dan Makassar menyebut ulama dengan sebutan "anreguru" dan "gurutta" penambahan " $t a$ " pada "gurutta" berarti "kita" jadi makna dari "gurutta" adalah "guru kita". Ada pun pengertian "anreguru" dari segi etimologi adalah rangkaian dua suku kata yang artinya berlainan antar satu dengan lainnya, kata "anre" dalam bahasa Bugis berarti "makan" dan "guru" juga berarti "guru" namun jika dilebur menjadi "anreguru" maknanya berubah menjadi "maha guru". Anregurutta atau Gurutta dan panggilan tersebut disematkan Khusus seorang ahli agama namun tidak untuk yang ahli dalam ilmu pengetahuan lainnya, ilmu agama dimaksud adalah terminologi ilmu-ilmu fardhu 'ain. ${ }^{3}$

Ilham (2017: 97) menyebutkan bahwa secara hirarkis, ulama Bugis juga betingkat-tingkat, yang tertinggi adalah panrita, lalu menyusul anregurutta, kemudian gurutta, dan para ustadz, hanya saja, seorang panrita disebut juga anregurutta dan gurutta, kedua gelar terakhir ini kerap berganti-ganti. Guru di sini dapat diartikan sebagai pendidik dalam pengertian yang lebih luas bukan sebagaimana kata "guru" menurut pengertian dari kamus-kamus bahasa Indonesia, hanyalah orang yang mata pencahariannya mengajar. Kata "guru" dapat digunakan untuk menyebut berbagai jenis orang yang mengajarkan sesuatu. Seperti para pengajar di sekolah, yang mengajar mengaji guru pangngaji, begitu pula para Imam kampung yang sering diminta membacakan doa untuk hajatan 
disebut guru pabbaca doang. Bahkan seseorang yang mengajarkan ilmu bela diri juga disebut guru pamenca'.

Syamsuddin Arief (2007) meneliti dari sudut pandang ulama Bugis yang terawal berkiprah di Sulawesi Selatan, K.H. Muhammad As'ad Al-Bugisi sekaligus sebagai aktor jaringan pesantren di Sulawesi Selatan. Dalam kajian ini, dapat ditarik benang merah bahwa Al-Bugisi selaku tokoh pelopor, sekaligus ulama perintis pondok pesantren di Sulawesi Selatan. Buktinya, hampir semua pesantren yang ada di Sulawesi Selatan pendirinya merupakan kader dari Al-Bugisi di Sengkang Wajo, karena itu, ia layak dijuluki sebagai arsitek pesantren. Salah satu yang cukup menonjol dari program kaderisasi ulama Al-Bugisi adalah K.H. Lanre Said yang mendirikan Pondok Pesantren AlQura'n Darul Huffadh, Tuju-Tuju, Kajuara, Bone, Sulawesi Selatan.

Palimai (2010) lebih spesifik dalam melakukan penelitian terhadap tokoh dan ulama hasil dari pendidikan kader ulama Al-Bugisi di bawah Madrasah Arabiyah Islamiyah (MAI) Sengkang. Tokoh di maksud adalah K.H. Lanre Said, penelitian ini cukup mendapat respon dari berbagai pihak, bahkan telah dijadikan bahan penelitian lanjutan oleh Universitas Islam Indonesia Yoyakarta; Litbang Kemenag Sulawesi Selatan, dan Komisi Informasi dan Komunikasi MUI Sulasesi Selatan. Namun, sebagai penelitian awal tentu saja karya ini belum terlalu memadai untuk mengungkap berbagai sisi kehidupan pribadi, pendidikan, dan jalan dakwah seorang Lanre Said.
Karya lain yang dapat dijadikan sebagai informasi tambahan adalah hasil dari Tim Penyusun (2010). Sayang Buku ini berbentuk fiksi, isinya bercampur antara fakta dan fiktif, dan tidak memiliki metodologi dan sistimatika penulisan yang jelas, tidak dapat dikategorikan sebagai karya ilmiah. Namun patut diapresiasi sebagai sebuah usaha untuk menyuguhkan informasi tambahan terkait riwayat hidup K.H. Lanre Said. Secara umum mengurai tentang lika-liku perjalanan K.H. Lanre Said ketika hendak mendirikan pondok pesantren. Begitu pula karya Zaitun Rasmin, (2018) yang lebih menyoroti kiprah ulama dalam memajukan pendidikan Islam di Indonesia, termasuk para ulama Bugis. Salah satu ulama Bugis yang memiliki peran penting dalam memajukan pendidikan adalah K.H. Lanre Said dengan mendirikan Pondok Pesantren Darul Huffadh pada 7 Agustus 1975. Ulama Bugis yang kini mendapat porsi kajian yang cukup laris dan menarik, sebagaimana karya Ilham (2017). Disertasi di Sekolah Pascasarjana UIKA Bogor, 2017 cukup menarik dalam pembahasannnya terkait ulama lokal seperti Al-Buisi dan muridmuridnya.. Disertasi ini memasukkan K.H. Lanre Said sebagai salah satu murid Al-Bugisi yang sukses menjadi ulama berpengaruh di Sulawesi Selatan.

Jenis penelitian ini berbentuk deskriptif kualitatif dengan menggunakan pendekatan sejarah sebagai bagian penting dalam acuan untuk menelusuri biografi tokoh (Syamsuddin, 2007: 89). Penelitian di lakukan di daerah Bone dan sasarannya adalah K.H.. Lanre Said. Ada pun jenis data yang dikumpulkan dalam penelitian ini meliputi: latar belakang keluarga dan 
riwayat pendidikannya; jalan dakwah yang ditempuh dengan cara berceramah pada Khalayak ramai, menulis buku, mengajar dan mendirikan pondok pesantren, sebagai suri teladan yang baik (ampe-ampe madeceng), serta pesan-pesan yang ia tinggalkan. Untuk mendukung penelitian ini, dipaparkan pula situasi dan kondisi kampung halaman di mana sang tokoh pernah hidup dan mengabdi. Sumber data adalah para informan yang memiliki kedekatan dengan K.H.. Lanre Said, seperti hubungan keluarga (istri dan anak), hubungan pertetanggaan, hubungan guru-murid dan hubungan pekerjaan. Selain itu, data sekunder dari bukubuku, jurnal, dan artikel yang relevan dengan penelitian.

Ada pun teknik pengumpulan data yang digunakan adalah: Wawancara dengan informan yang relevan yakni keluarga atau kerarab ulama yang bersangkutan, orang-orang yang memiliki kedekatan dengannya terutama mereka yang pernah hidup bersama sebagai santri dan guru dengan masa yang lama, serta anggota masyarakat lainnya; Studi pustaka dan dokumen yang berkaitan dengan penelitian. Obsevasi tentu wajib dilakukan dalam rangka membaca lingkungan masyarakat sekitar ulama yang diteliti, terutama kehidupan keagamaannya sebagai bagian dari cara mendapatkan data penunjang. Sebagai ciri penelitian kualitatif, instrument utamanya adalah peneliti sendiri, maka pengolahan data dilakukan bersamaan dengan pengumpulan data. Kritik sumber, baik eksternal maupun internal terhadap data yang terkumpul (evidensi) dilakukan pada pengolahan ini. Berikutnya, data dikategorikan berdasarkan jenis tertentu, lalu disusun dalam sebuah pola atau sistematika. Analisis data yang digunakan harus sesuai dengan jenis data yaitu deskriptif kualitatif dalam bentuk narasi. Penelitian ini bermula pada awal Agustus 2018 dan selesai pada awal Januari 2019.

Berdasarkan dengan pendahuluan di atas maka secara langsung peneliti dapat mengambil rumusan masalah yang akan menjadi dasar dalam menguraikan dan menjawab permasalahan yang ada terkati K.H. Lanre Said. Pertama, bagaimanakah biografi dan latar belakang pendidikan K.H. Lanre Said?; Kedua, bagaimanakah jalan dakwah yang dipilih dan ditempuh oleh K.H. Lanre Said?; Apa saja pesan dan wasiat yang diberikan K.H. Lanre Said kepada para santrinya. Pertanyaan-pertanyaan di atas akan dijawab dalam artikel ini. Rumusan masalah ini sekaligus menjadi pembatasan masalah terkait K..H Lanre Said yang begitu banyak, namun karena keterbatasan ruang sehingga fokus pembahasan hanya terkait tiga masalah di atas.

\section{PEMBAHASAN}

Kabupaten Bone merupakan salah satu Daerah otonom di provinsi Sulawesi Selatan, Indonesia. Ibu kotanya terletak di kota Watampone. Berdasarkan data Kabupaten Bone Dalam Angka Tahun 2015 yang diterbitkan Badan Pusat Statistik Kabupaten Bone, jumlah penduduk Kabupaten Bone Tahun 2015 adalah 738.515 jiwa, terdiri atas 352.081 laki- laki dan 386.434 perempuan. Dengan luas wilayah 
Kabupaten Bone sekitar $4.559 \mathrm{~km} 2$ persegi, rata- rata tingkat kepadatan penduduk Kabupaten Bone adalah 162 jiwa per $\mathrm{km} 2 .{ }^{4}$

Ada pun dari segi territorial, Kabupaten Bone sebelah selatan perbatasan dengan Sinjai dan Gowa, sebelah utara, perbatasan dengan Wajo dan Soppeng, sedangkan sebelah timur perbatasan dengan Teluk Bone, dan bagian barat perbatasan dengan Maros Pangkep dan Barru. Selain kedua wilayah yang terkait dengan iklim tersebut, terdapat juga wilayah peralihan, yaitu: Kecamatan Bontocani dan Kecamatan Libureng sebagian mengikuti wilayah barat dan sebagian lagi wilayah timur. ${ }^{5}$

Dituliskan bahwa setelah daerah dan kerajaan-kerajaan lain di Sulawesi Selatan memeluk agama Islam, maka Sultan Alauddin Awwalul Islam adalah dai yang tak kenal lelah mengajak para raja-raja untuk memeluk Islam, termasuk dalam Raja Bone, La Tenri Ruwa (1607-1608) kakek Arung Palakka dari putrinya We Tenri Sui' yang saat itu baru tiga bulan dilantik menjadi Raja Bone, ternyata beliau merespon dengan sangat baik ajakan koleganya itu, meski pada saat itu tidak langsung mengucapkan dua kalimat syahadat. La Tenri Ruwa kembali ke Bone mengumpulkan rakyatnya dan berseru agar ajaran agama Islam diterima sebagai agama resmi kerajaan, tetapi sayang, niat baik Sang Raja mendapat protes ketidak-setujuan dari para rakyatnya (Palimai, 2010: 32).

Beliau terus berusaha meyakinkan rakyatnya namun tetap gagal maka ia

${ }^{4}$ https://bone.go.id/ pun mengumumkan dirinya mundur sebagai Raja dan diam seribu bahasa. Rakyat bingung, dan merasa kehilangan, maka mereka mengirim utusan untuk bertemu Sang Raja, utusan itu berkata, "Bukan kami yang tidak menyukai puatta', tapi puatta'lah yang tidak menyukai kami”. Raja La Tenri Ruwa kemudian menjawab, "Saya menerima ajakan dari rekan kami Raja Gowa Sultan Alauddin bukan karena takut padanya, melainkan karena saya meyakini kebenaran agama yang dibawanya, silahkan kalian berpegang pada ajaran kalian yang menyesatkan itu". Raja kemudian digantikan oleh $L a$ Tenri Pole Arung Timurung (Kadir, 2012: 58).

Pada awalnya Sultan Alauddin bertekad menyebarkan Islam di Bone secara damai tanpa konfrontasi fisik, bahkan berniat mengutus Datuk Ribandang ke Bone, namun selalu menemui kegagalan karena keengganan rakyat Bone untuk memeluk Islam baik dari kalangan penguasa maupun masyarakat biasa. Maka perang tak dapat dielakkan sebagai alternatif terakhir, perang ini pun menjadi perang agama bagi raja kembar Gowa-Tallo dan harga diri bagi Raja Bone, perang ini juga terkenal dengan istilah Buduk Sallanga, Musu' Asselengeng alias "musuh bebuyutan" (Ilham, 2017: 138).

Bone akhirnya tak kuasa melawan gempuran dan akhirnya bertekuk lutut, kemudian rajanya La Tenri Pole pergi menghadap Sultan Alauddin dan memeluk Islam bersama seluruh rakyatnya. Kemudian Sultan bertitah, "Meskipun kalah perang tetapi karena Islam diterima baik di kerajaan Bone,

\footnotetext{
5 https://bone.go.id/2016/04/30/luas-wilayah-
} menurut-kecamatan-di-kabupaten-bone/) 
maka dibebaskan dari pampasang perang begitu pula semua tawanan dibebaskan". Mendengar titah Sultan itu maka rakyat Bone mulai berduyungduyung masuk agama Islam. La Tenri Pole yang sudah memeluk Islam kemudian bergelar Sultan Abdullah, setelah wafat sebagaimana wasiatnya agar digantikan oleh La Maddaremmeng Arung Timurung yang bergelar Sutan Muhammad Saleh diangkat sebagai pelanjut. (Kadir, 2012: 59).

Walaupun Islam sudah lama bercokol dan berkembang di Bone namun, bukan berarti masyarakatnya benarbenar telah paham agama Islam dan menjalankan ritual agama sesuai dengan ajaran yang telah dicontohkan oleh para sahabat Nabi dan generasi salaf setelahnya. Di daerah Bone masih kita jumpai praktik-praktik ritual keagamaan yang bersifat budaya. Sangat sulit membedakan antara budaya dan agama, terkadang masyarakat awam memandang bahwa keduanya adalah bagian dari ajaran agama, upacara-upacara adat berbau agama masih dilestarikan, seperti memotong sapi untuk dipersembahkan bagi orang yang telah meninggal. Selain itu, masyarakat Bone juga masih memelihara tradisi upacara keagamaan seperti perayaan maulid dan isra mikraj yang memang dirayakan secara nasional.

\section{Biografi Singkat K.H. Lanre Said : Kehidupan Pribadi dan Pendidikan}

Lanre Said dilahirkan pada tahun 1923 M, tidak diketahui pasti hari, tanggal dan bulannya, di sebuah kampung bernama Ulunipa atau Manera
Salomekko Kabupaten Bone dan merupakan anak kedua dari pasangan Andi Passennuni Petta Ngatta dengan Andi Marhana Petta Uga. Nama kecilnya adalah Andi Muhammad Said, namun setelah masuk belajar di Madrasah Arabiyah Islamiyah Sengkang namanya diubah oleh AlBugisi menjadi Lanre Said. Merupaka anak kedua dari tujuh bersaudara, tumbuh dan berkembang di bawah asuhan dan didikan ayahnya, namun setelah berumur sepuluh tahun beliau dikirim untuk belajar di MAI Sengkang pada tingkat Tahdiriyah untuk manyusul kakaknya Petta Haji Lesang yang terlebih dahulu telah tinggal dan mondok di bawah asuhan langsung oleh Al-Bugisi (Palimai, 2010: 49).

Lanre Said berasal dari keluarga yang taat dalam agama dan peduli terhadap pendidikan terutama ilmu-ilmu agama, ini terbukti dari tujuh bersaudara mereka semuanya pernah belajar dan mondok di MAI Sengkang, adikadiknya yang turut serta mondok dan belajar di bawah asuhan Al-Bugisi adalah Petta Haji Sikki, Petta Haji Dollah, Petta Hj. Sokku, Petta Lebbi, dan Andi Abdul Malik Petta Simpuang, adapun yang paling bungsu disebut di atas ia hanya mondok di MAI saja namun melanjutkan sekolah formal di luar pondok tepatnya di Madrasah Ibtidaiyah Muhammadiyah Sengkang. Dikisahkan bahwa ibunya pernah mendapatkan Lailatul Qadar dan berdoa agar dikaruniai tujuh keturunan ulama yang kesemuanya hafal Al-Qur'an dan penghuni surga. ${ }^{6}$

Lanre Said menghabiskan waktunya untuk belajar di MAI dari tahun 1932

${ }^{6}$ Andi Siti Nurhasanah, wawancara di Palattae, 8 Agustus 2018 
hingga 1946, atau selama 14 tahun, dengan rincian Tahdiriyah 3 tahun, Ibtida'iyah 4 tahun, Tsanawiyah 3 tahun dan halaqah Khususkader ulama 2 tahun. Dalam umurnya yang menginjak 23 tahun Lanre Said telah menyelesaikan seluruh jenjang pengabdian MAI Sengkang. Setelah itu berliau mengajar pada almamaternya pada tahun 1944 hingga 1948, atau selama empat tahun, pada aK.H.ir tahun 1948 ia kembali ke kampung halamannya di Tuju-tuju untuk mengabdikan diri dengan mengajar dan berdakwah, kemudian selanjutnya dinikahkan dengan serang gadis belia yang masih tergolong kerabatnya yang juga berasal dari Tuju-tuju bernama Siti Qashodiyah Sakke. Setelah menikah dan bermukim di Tuju-tuju untuk selama dua tahun beliau menyeberang ke sebuah pulau di daerah Kabupaten Selayar yaitu Pulau Jampea, di sana merintis lembaga pendidikan Islam formal setingkat dengan Sekolah Lanjutan Tingkat Pertama yang kurikulumnya berafiliasi ke MAI Sengkang. Cuma saja sekolah ini tidak mewajibkan kepada seluruh siswanya untuk berasrama, para masyarakat Jampea sangat menerima kehadiran Lanre Said di sini dengan senang hati, oleh karena itulah beliau sangat betah bermukim dan menjadi guru di kepulauan ini (Palimai, 2010: 51).

Pada tanggal 7 Agustus 1953, Komandan Tentara Keamanan Rakyat (TKR) di daerah Sulawesi Selatan Abdul Qahhar Muzakkar memproklamasikan penggabungan pasukan dan daerah yang dikuasainya kedalam Negara Islam Indonesia (NII) di bawah pimpinan Kartosuwirjo yang berpusat di Jawa Barat. Dengan bergabungnya Qahhar Muzakkar ke dalam NII maka secara otomatis jaringan NII ini yang telah diproklamerkan oleh Kartoswirjo pada 7 Agustus tahun 1949 bertambah luas. (Gonggong, 2004: 212). Untuk menopang perjuangan NII maka Kartoswirjo membentuk angkatan bersenjata yang diberi nama Gerakan Darul Islam/Tentara Islam Indonesia (DI/TII) yang digunakan untuk mempertahankan eksistensinya, termasuk menentang pasukan dan pemerintahan Republik Indonesia yang tidak setuju tentang perjuangan, visi, dan misi NII (Awwas, 2015: 274). Diperkirakan pada tahun 1953 setelah setelah dua tahun merintis sekolah dan mengajar di Pulau Jampea Selayar tahun 1952-1953 dan bertepatan pada tahun diproklamasikannya penggabungan pasukan Qahhar Muzakkar dan pasukannya yang dikuasainya ke dalam NII, Lanre Said bergabung bersama DI/TII dengan Qahhar Muzakkar (Palimai, 2010: 53).

Selama bergabung dengan pasukan DI/TII bahwa karir Lanre Said sangat cemerlang, bermula dengan menjadi Kepala Kepolisian DI/TII kemudian dipindahkan menjadi Imam Tentara yang merupakan Panglima Tertinggi, dan yang terakhir adalah Ketua Mahkamah Agung, ketika itulah ia tidak setuju karena merasa tanggungjawabnya sangat besar baik terhadap manusia ataupun di hadapan Allah kelak, di samping itu merasa belum pantas karena umurnya saat itu masih terlalu mudah untuk menyandang ketua MA, memang jika dibandingkan dengan para rekannya Lanre Said termasuk yang termudah di antara mereka, namun karena keputusan pengangkatannya merupakan keputusan musyawarah 
dewan tertinggi DI/TII dan penunjukannya langsung di bawah Qahhar Muzakkar maka Lanre Said tidak bisa berkutik lagi dan akhirnya dia pun menerima tanggungjawab berat ini. $^{7}$

Dalam menjalankan tugasnya ia berpindah-pindah dari satu daerah ke daerah lain hal ini dapat dipahami karena selama bergabungnya pasukan Qahhar Muzakkar ke dalam DI/TII ini terus mendapat hambatan dari pihak pemerintah Republik Indonesia di bawah pasukan TNI. Cara DI/TII menjalankan pemerintahannya juga tergolong sederhana yaitu dibagi menjadi pusat sebagai pemegang kendali utama dan distrik sebagai perpanjangan tangan dari pusat atau disebut juga daerah kekuasaan. Pusat pemerintahan bertempat di daerah asal Qahhar Muzakkar yaitu di Luwu, daerah lain seperti, Enrekang, Sengkang, Bone, Sinjai, Soppeng, dan lainnya merupakan distrik. ${ }^{8}$

Daerah Bone bagian selatan misalnya, pemerintahan dikendalikan oleh distrik yang meletakkan pusat pemerintahannya di daerah Patimpeng tepatnya di Bulu' Bilalang (Gunung Bilalang), sebagai Ketua Mahkamah Agung Pusat maka Lanre Said harus terjun ke daerah-daerah termasuk dalam hal ini ke Bulu' Bilalang. Ketika bertugas di distrik ini Lanre Said dikenalkan dengan seorang gadis jelita bernama Andi Siti Nurhasanah asal Arallae sebuah kampung yang bersebelahan dengan Patimpeng, lewat perantaraan seorang guru agama bernama Ustad Asaf, singkat cerita tahun 1957, malam Jumat 29

7 Andi Mukhtar Longi, wawancara di Palattae, $8 / 08 / 2018$
Ramadhan, Lanre Said resmi mempersunting Andi Siti Nurhasanah yang kemudian dikenal dengan Petta Cinnong sebagai Istri keduanya. Tidak begitu lama Ketua Mahkah Agung DI/TII ini menikah untuk yang ketiga kalinya dengan Petta Suruga dan dua tahun kemudian kembali menikah untuk keempat kalinya dengan Andi Banunah Petta Paccing di daerah Hadong, Masago Patimpeng (Palimai, 2010: 54).

Saat bertugas di Bulu' Bilalang ini adalah peristiwa besar pada diri Lanre Said, di sana dia bermimpi menyalakan lampu untuk menerangi kegelepan, lampu itu dinyalakan di puncak Gunung Bilalang dengan menggunakan lampu petromaks dalam bahasa bugis disebut lampu strongkeng, dalam mimpinya beliau melihat cahaya di sekitar lampu tersebut sangatlah terang-benderang namun di bawahnya kelihatan remang-remang bahkan nyaris gelap. Mulai dari saat itulah ia berusaha untuk mencari takwil mimpi tersebut, dan dengan metode tersendiri yang beliau dapatkan dari guru-gurunya serta pengalaman pribadinya dalam cara menakwilkan mimpi maka ia berkesimpulan kalau arti dari mimpinya itu adalah perintah untuk mendirikan lembaga pendidikan yang dapat memancarkan iman dan ilmu sebagai sumber cahaya bagi ummat ini, tanpanya manusia akan menjadi gelap dan sesat tanpa arah tujuan sehingga sangat mudah disambar oleh setan dari jenis manusia dan jin. Setelah itu Lanre Said berusaha mencari tempat yang sesuai untuk mendirikan lembaga 8 Andi Mukhtar Longi, wawancara di Palattae,
$8 / 08 / 2018$ 
pendidikan yang berlandaskan dengan Al-Qur'an dan Hadis shabih. ${ }^{\text {' }}$

Walaupun Lanre Said masih tetap menjabat sebagai Ketua Mahkamah Agung NII-DI/TII namun pada dasarnya setelah mendapatkan perintah dari Allah untuk mendirikan lembaga pedidikan lewat mimpi tersebut ia mulai berpikir untuk keluar dari pasukan Qahhar Muzakkar ditambah lagi saat itu sebagian anggota DI/TII sudah banyak yang menyalahi aturan syariat Islam sendiri seperti merusak fasilitas umum, membakar pemukiman penduduk, membuat onar, dan berbagai pelanggaran lainnya, hal ini dapat dimaklumi menurut Lanre Said karena terlalu banyaknya anggota baru yang direkrut masuk dalam pasukan DI/TII tanpa melewati mekanisme pembinaan. ${ }^{10}$

Setelah melalui perjalanan panjang dan berliku dalam hidupnya, serta seluruh obsesi dan cita-cita mulianya terwujud maka pada akhirnya ajal datang menjemputnya, sebagai satu kesniscayaan, kita rela atau tidak tamu yang satu ini pasti akan datang pada setiap mahluk Allah, kita semua juga demikian adanya hanya waktu saja yang membedakan, ada yang cepat ada pula yang lambat serta yang terbaik dari semuanya hanyalah yang meninggalkan karya yang mendatangkan manfaat pada segenap manusia, dan Lanre Said sudah membukakan jalan untuk kita semua agar kita juga dapat berkarya dan berbuat baik seperti dirinya. Di usianya yang menginjak ke 82 tahun setelah terserang penyakit stroke pada malam Minggu 21 Mei 2005 yang keesokan harinya membawanya harus dilarikan

${ }^{9}$ Muttaqin Said, wawancara di Palattae, 08/08/2018 ke rumah sakit umum daerah Sinjai namun di sana tidak bertahan lama hanya berselang dua hari kemudian tepatnya pada jam 13.30 hari selasa 24 Mei 2005 di dalam rumah sakit ini Lanre Said menghembuskan nafas terakhirnya. Dan keesokan harinya beliau dikuburkan dalam tanah yang memang telah ia persiapkan untuk dirinya sendiri semasa hidupnya yang berlokasi di dalam kawasan Pondok Pesantren Darul Huffadh, Tuju-tuju. Semasa hidupnya Lanre Said pernah menikah sebanyak empat kali, masingmasing adalah $\mathrm{Hj}$. Qashodiyah yang melahirkan seorang putri bernama $\mathrm{Hj}$. Rasdiana Said; Hj. Andi Nurhasanah Petta Cinnong melahirkan dua putra, MuK.H.lias Said (alm) dan Dr. Muttaqien Said, MA; Hj. Suruga melahirkan seorang putra bernama Drs. Andi Mustaqim Said, M.Si; Andi Banunah Petta Paccing yang melahirkan tujuh anak yaitu, Dra. Sa'adah Said, Dra. Sa'idah Said, Saad Said, S.Ag., Suadah Said, Su'ud Said, Sa'diah Said, dan Sabiah Said. Dari pernikahannya dengan empat istri tersebut melahirkan duabelas keturunan, namun perlu dicatat Lanre Said tidak pernah hidup bersama dengan keempat istrinya dalam satu masa (Palimai, 2010: 62-63).

\section{Jalan Dakwah K.H. Lanre Said}

Secara umum, tempat reproduksi ulama dalam masyarakat Bugis tidak berbeda dengan di Jawa, yaitu berasal dan berawal dari pesantren lalu diaplikasikan ilmunya, dan dimatangkan di tengah masyarakat. Pengetahuan yang selama ini bersifat teroritis di pesantren akan diuji di

10 Andi MuK.H.tar Longi, wawancara di Palattae, 08/08/2018 
tengah masyarakat. Proses pematangan yang melibatkan ketiga komponen di atas akan menjadi penentu eksistensi seorang ulama Bugis (Ahmad, 2008: 422). Demikian pula dengan Lanre Said, sebagai seorang ulama besar di tanah Bugis tentu memiliki kiprah yang diakui oleh masyarakat setempat, para masyarakat yang akan menilai sedalam mana keilmuan sang ulama, dan sebesar apa pengorbanan dan sumbangsihnya kepada umat, sebesar apa kontribusinya dalam mencerdaskan kehidupan bangsa, serta apa yang ia laksanakan dalam menuntun umat ke jalan yang benar. Pada bagian ini akan memaparkan jalan dakwa K.H. Lanre Said semasa hidupnya.

Pertama, berdakwah dengan ceramah agama. Sebagai seorang ulama yang memiliki semangat yang gigih desertai dengan mobilitas yang tinggi, terutama dikala fisiknya masih mendukung, ini dapat dibuktikan dengan melalui perjalanan panjangnya keliling dari satu tempat ketempat lain, mulai di Sulawesi sendiri Selanjutnya ke Kalimantan, ke Nusa Tenggara Timur (NTT), ke Sumbawa (NTB), dan ke Surabaya Jawa Timur, Cirebon Jawa Barat, dan selanjutnya kembali ke Sulawesi Selatan. Di Sulawesi Selatan, daerah Kabupaten Bone umumnya dan Bone Selatan Khususnya, meliputi, Kecamatan Cina, Mare, Tonra, Salomekko, Kajuara, Palattae, Bonto Cani, dan Kabupaten Sinjai adalah merupakan lahan dakwah Lanre Said. ${ }^{11}$

Dalam ceramah-ceramahnya beliau menggunkan bahasa Bugis sebagai bahasa pengantar utama, oleh karena itu selain yang tidak faham bahasa

11 Andi MuK.H.tar Longi, wawancara di Palattae, 08/08/2018
Bugis tentu saja kesulitan untuk memahami isi ceramahnya, dalam hal ini termasuklah para santri-santrinya sendiri yang bersal dari luar suku Bugis, namun para santri tidak kehabisan akal, biasanya mereka merekam dikala Lanre Said sedang berceramah kemudian diterjemahkan kedalam bahasa Indonesia. Isi ceramahnya, tergantung kadar pemahaman agama masyarakat tempatnya berceramah (kondisioner). Kalau masyarakatnya masih kental dengan budaya animisme dan dinamisme maka beliau membahas tentang pemurnian aqidah, namun jika penduduk setempat banyak yang mengamalkan bid'ah maka materinya yang berhubungan dengan bahaya bid'ah dan ancaman bagi pelakunya disertai cara pemberantasan bid'ah itu sendiri, tetapi jika para pendengarnya dari kalangan pejabat atau dari istansi pemerintahan maka pokok pembahasan ceramahnya banyak yang berhubungan dengan hukum-hukum, baik syariat maupun muamalat. ${ }^{12}$

Di antaranya adalah terkait dengan hukum bunga bank konvensional yang sejak dari awal-awal lagi Lanre Said dalam setiap ceramah dan pendapatnya mengatakan haram. Namun jika para jamaahnya sudah taat dalam artian bebas dari berbagai macam pelanggaran besar dalam agama, biasanya materi ceramahnya agak lebih santai tapi tetap mengena, di antara isi ceramahnya adalah sejarah-sejarah para umat terdahulu, mulai dari kisah penciptaan makhluk-makhluk dan umat-umat sebelum Nabi Adam, kemudian masuk pada penciptaan manusia diawali dengan Nabi Adam hingga Nabi Muhammad SAW

12 Muhammad Nasir, wawancara di Tuju-Tuju, 02/01/2019 
(termasuklah kisah-kisah para rasul yang 25 dari masa lahirnya hingga diutus menjadi rasul dan sampai wafat) selanjutnya beliau bercerita tentang halhal yang berlaku setelah kematian atau keadaan dalam kubur sampai alam akhirat yang di dalamnya ada surga dan neraka. ${ }^{13}$

Pada dasarnya K.H. Lanre Said dalam berdakwah lewat ceramah-ceramah tidak terlalu maksimal hasilnya pada sebagian besar jamaah atau masyarakat pada umunya. Faktor utama yang menjadikan Lanre Said kurang populer dalam berdakwah lewat ceramah adalah metode dakwahnya yang blak-blakan, tidak ada toleransi dalam hal pelanggaran aqidah dan syariat, tidak segan-segan menyindir para aparat pemerintah dan keamanan, ditambah lagi masyarakat sekitar kediaman beliau adalah masyarakat yang masih kental budaya tahyul, bid'ah dan Khurafatnya, (bid'ah akidah dan ibadah), sedang inilah yang sangat ditekankan oleh beliau dalam setiap cerahmahnya, oleh karena itulah selalu dicekal, bahkan tidak jarang terjadi intimidasi dari aparat setempat yang mengancam jiwanya. ${ }^{14}$

Pada dasarnya orang-orang di sekitar pondok pesantren atau kediaman Lanre Said sangat menerima keberadaan beliau, disamping karena berasal dari keturunan darah biru anakarung, orang Bone menyebutnya andi atau petta, kalau di jawa adalah keturunan ningrat dan disebut raden, keberadaanya di daerah Tuju-Tuju dipercaya membawa banyak berkah (mabbarakka'), betapa tidak, daerah

${ }^{13}$ Azhar Azis, wawancara di Batam, 07/12/2018

14 Muhammad Nasir, wawancara di Tuju-Tuju, 02/01/2019 yang sangat tidak populer ini di banding dengan daerah-daerah di sebelahnya, sangat mengejutkan karena bisa dikenal hingga di luar Sulawesi bahkan dari luar negeri. Seakan daerah ini menjadi gula yang selalu diincar oleh para semut yang datang dari berbagai penjuru, yang tidak diterima oleh penduduk Tuju-Tuju sendiri adalah terkait lebih kepada pemahamannya yang dianggap tidak sama oleh para nenek moyang dan pendahulupendahulu mereka. Walaupun pada dasarnya masyarakat Tuju-Tuju memahami bahwa apa yang diajarkan oleh Lanre Said adalah benar, hanya saja mereka belum mampu melakukan, dan sebagian lainnya merasa sungkan. Ini terbukti, pasca wafatnya Lanre Said, masyarakat Tuju-Tuju berbondongbondong memasukkan anaknya untuk belajar di Pondok Pesantren Darul Huffadh. ${ }^{15}$

Kedua, Berdakwah dengan Tulisan. K.H. Lanre Said adalah ulama Bugis yang cukup produktif, walau aktifitasnya sangat sibuk dalam mengasuh dan mendidik para santri, malayani tamu yang datang silih berganti, dan memenuhi undangan mengisi ceramah di berbagai tempat, ia masih sempat menulis buku yang cukup banyak. Karya tulis yang dihasilkan Lanre Said ini tidak berlebihan, jika diibaratkan dengan Ibnu Taimiyah dalam memberantas tahyul, K.H.urafat, dan bid'ah lewat tulisan pada zamannya. Buku yang ditulis oleh seorang yang memiliki ilmu pengetahuan yang luas, serta mata batin bashirab yang tajam ini adalah buku panduan dalam melaksanakan ibadah

\footnotetext{
15 Muhammad Nasir, wawancara di Tuju-Tuju, 02/01/2019
} 
dengan baik dan benar sesuai dengan tuntunan al Qur'an dan Sunnah Nabi. Nama bukunya, "Adz-Dzikra", Lanre Said sendiri tidak pernah menerangkan baik secara bahasa maupun arti secara istilah, apa makna dan ia maksud dengan judul buku di atas. Namun, jika Mengambil makna dari sebuah ayat dalam al-Qur'an 52:55. "Fadrakkir fainna adz diikera tanfa'ul mu'minin", maka, Adz-Dzikra, menurut bahasa adalah peringatan, besar kemungkinan Lanre Said menggunakan nama ini karena melihat fenomena masyarakat disekitarnya yang terus-menerus mengamalkan tahyul, bid'ah, dan Khurafat. Dan seakan-akan hatinya tertutup untuk menerima kebenaran, bahkan ultimatun demi ultimatun yang disampaikan kepada mereka tapi tetap saja membangkan, hal ini berlaku pada masyarakat Tuju-tuju Kajuara kala buku itu ditulis, sejak beliau menetap di Tuju-tuju tidak pernah di undang untuk ceramah oleh orang Tuju-tuju sendiri lebih Khususnya lagi setelah menerbitkan buku ini pada tahun 1975 , namun tawaran justru sering berdatangan dari kecamatan lain seperti Salomekko, Palattae, hingga Kabupaten Sinjai (Palimai, 2010: 73).

Buku "Adz-Dzikra" ditulis pada tahun 1975 dan masih menggunakan ejaan lama, dan hanya dikonsumsi untuk kalangan sendiri, buku ini juga merupakan jawaban atas tamu dan keluarga atau siapa saja yang datang pada beliau untuk menanyakan perkara-perkara agama, Khususnya yang berhubungan dengan ibadah yang berbentuk asasi, seperti taharah, sholat, dan sebagainya, disamping permintaan dari beberapa kalangan yang ingin mengetahui tata cara beribadah dengan jelas dan ringkas. Karena cetakan dan tulisannya masih menggunakan ejaan lama (ejaan yang belum disempurnakan), dan terdapat beberapa tulisan yang kurang jelas disertai jumlah murid yang kian hari kian bertambah dan tentu saja memerlukan buku di atas, maka pada awal tahun 1990-an, Lanre Said kembali menulis Adz Dzikra dengan tulisan versi ejaan yang telah disempurnakan dibantu dengan beberapa guru-guru yang memiliki tulisan Arab (khat) yang indah. Sehingga penulisannya sudah jauh lebih sempurna dan dijadikan buku wajib bagi para santri.

Ada pun karya-karyanya adalah: Taharah; Perintah Shalat; Shalat Nawafil (shalat-shalat sunnat); Urusan Jenazah; Beberapa Masalah A - E (Said, 1995). Buku "Adz-Dzikra" terbagi menjadi beberapa bagian, bagian pertama meliputi, taharah, perintah sholat, shalat nawafil, dan urusan jenazah, ada pun bagian kedua membahas tentang beberapa masalah, yang terdiri dari empat jilid, 5A sampai 5E. Sejatinya buku ini disusun juga tidak terlepas dari koreksi terhadap ceramah dan pengaiian-pengajian yang telah disampaikan ketikan baru lulus belajar di pondok pesantren Madrasah Arabiyah Islamiyah Sengkang, yang pada masa itu masih lagi mengamalkan hal-hal yang berbau bid'ah dalam beribadah, namun setelah tahun 1962 barulah pemahamannya tentang perkara bid'ah mendalam dan selanjutnya memusuhinya, termasuk meralat seluruh ucapannya baik lewat ceramah maupun lewat tulisan.

Ketiga, Berdakwah dengan Mengajar Para Santri. Sejak beliau masih belajar di bawah asuhan Al-Bugisi dari MAI 
Sengkang, Lanre Said sudah mulai mengajar. Ketika duduk pada jenjang Tsanawiyah maka ia telah diberi wewenang untuk mengajar para santri yang berada pada jenjang pendidikan di bawahnya, seperti Tahdiriyah dan Ibtida'iyah, dan ketika duduk pada level taK.H.asus atau kader Khususulama, Lanre Said bahkan telah mengajar pada jenjang Tsanawiyah yang hakikatnya merupakan jenjang tertinggi saat itu. Ada pun kelas Khususpendidikan kader ulama, maka tidak semua santri mampu ikut program tersebut (Ilham, 2018).

Demikian pula, setelah dinyatakan lulus sebagai ulama dari MAI Sengkang pada tahun 1944, maka ia pun mengabdi hingga tahun 1948, setelah itu baru kembali ke kampung halamannya di Tuju-Tuju kemudian menikah, menetap dan mengajar di sana. Dua tahun mengajar masyarakat Tuju-Tuju, akhirnya menyeberang ke Pulau Jampea yang masuk dalam Kabupaten Selayar. Di sana dia mengajar, bahkan mendirikan lembaga pendidikan. Tidak lama kemudian, ketika terjadi pemberontakan DI/TII pada 7 Agustus 1949, Lanre Said ikut bergabung dan dipercaya menjadi imam dan guru bagi pasukan angkatan bersenjata DI/TII. ${ }^{16}$

Karena ketertarikan mengajar sekaligus menjadi panggilan jiwa dan cita-citanya sehingga pada akhirnya Lanre Said mendirikan pondok pesantren yang ia namakan Majelisul Qurra' wal-Huffaz. Rumah panggung beratap daun rumbia tempatnya menetap sebagai awal mula berdirinya Majlisul Qurra' Wal Huffadz yang dimulai pada Jam 07.00 Tangggal

16 Andi Siti Nurhasanah, wawancara di Palattae, 08/08/2018
7 Agustus 1975 berlokasi di kampung Tuju-Tuju dan dimulai dengan 7 jumlah santri yang langsung di pimpin oleh Lanre Said. Dengan fasilitas yang serba minim, tidak menyurutkan sama sekali semangat Lanre Said untuk maju ke depan mengerjar cita-citanya (Rasmin, 2018: 73). Padahal rintangan pada saat-saat awal berdirinya pondok Majlisul Qurra' Wal Huffadz tidaklah sedikit, bukan saja karena fasilitasnya yang minim tetapi juga pihak pemerintah yang tidak melegalkan bahkan menghalang-halangi keberadaan pondok ini. Saat itu, ruang mengajar Lanre Said hanya di bawah kolong rumah tempat tinggalnya yang berukuran 32 Meter persegi, materi pelajarannya pun sangat sederhana, bahkan jumlah santrinya yang sama dengan jumlah hari dalam seminggu tersebut kerap diajak oleh Lanre Said bekerja membuat empang untuk kebutuhan lauk pauk para santri (Rasmin, 2018: 74).

Pada awal tahun 1990-an angin segar mulai menerpa pesantren, Bapak Bupati Bone Andi Muhammad Amir, lewat mediator Petta Muharram ayah dari Bapak Bupati sendiri, untuk membantu agar MQWH dapat dilegalkan dari sisi kelembagaan dan keberadaannya. Dalam artian sudah bebas untuk melakukan segala bentuk kegiatan tanpa ada yang menghalanginya sebagaimana yang telah berlaku selama ini. Dan mulailah dilakukan tertib administrasi, Ustad Anwar Harum bahkan ke Makassar ke aktanotaris membuat yayasan yang menaungi Pondok Pesantren Darul Huffadh, termasuk mengirim laporan pada pihak-pihak yang berwenang 
untuk mengetahui program dan perkembangan pondok. ${ }^{17}$

Puncaknya pada tanggal 11 Nopember 1992 adalah perubahan nama dari "Majelis al Qurra' wal Huffadh" ke "Darul al Qurra' wal Huffadh" yang pada saat itu dikonsep langsung oleh Muttaqien Said di Bantu dengan para guru-guru, jadi kata "Majelis" diganti menjadi "Darul" berarti tempat, pada dasarnya dari segi makna tidak begitu jauh berbeda, namun secara umumnya perkataan yang ke dua ini lebih umum ditujukan kepada nama lembaga pendidikan yang bernuansa pondok pesantren di Indonesia. Namun tidak lama kemudian melalui pertimbangan dan catatan tersendiri dari Muttaqien Said, maka beliau selanjutnya menghilangkan kata al Qurra' dan selanjutnya disederhanakan menjadi "Darul Huffadh". ${ }^{18}$

Keempat, Berdakwah dengan Uswatun hasanah. Ini adalah kompetensi terkahir bagi ulama Bugis, selain ilmu yang tinggi, pengabdian tanpa batas, tulus dalam berbuat, yang tak kalah penting adalah mampu menjadi suri teladan yang baik. Ini merupakan kepribadian yang disebut adab dan akhlak. Sebab, menurut Al-Attas (2011: 187) tujuan pendidikan hakikatnya adalah membentuk manusia beradab (Wan Daud, 2003: 174, Kadir, 2013), hanya mereka yang beradab akan mampu menjadi orang shaleh inilah dibahasakan oleh masyarakat Bugis sebagai ampe-ampe madeceng, atau prilaku yang elok. Suri teladan dari adab adalah bersumber dari golongan yang berilmu, Khususnya para ulama sebagai sumber ilmu dan pengganti peran para nabi.

${ }_{17}$ Muttaqin Said, wawancara di Palattae, 08/10/2018

${ }_{18}$ Muttqin Said, wawancara di Palattae, 08/08/2018
Sebagai panutan, tentu banyak hal yang dapat dijadikan teladan dalam diri Lanre Said, tulisan ini hanya menyuguhkan sebagian kecil saja yang akan menjadi gambaran terhadap diri ulama yang sedang kita bahas ini. Dalam sisi keilmuan, Lanre Said sangat layak dijadikan contoh bagi para santri yang hendak mengikuti jejaknya. Penguasaannya terhadap ilmu-ilmu alat berupa bahasa Arab yang meliputi ilmu sharaf, nahwu, dan balaghah sangat mendalam. Termasuk ilmu-ilmu asas bagi yang hendak menjadi ulama mujtahid yang meliputi ilmu ushul fiqh, ilmu ushul at-tafsir, ilmu musthalah hadits, hingga ilmu manthiq. Jika ilmuilmu tersebut sudah dikuasai maka menurut Lanre Said, untuk menelaah materi dari aqidah, tafsir, hadis, dan fikih tentu tidak sulit. Dan, yang paling menonjol dari diri Lanre Said adalah hafalan al-Qur'annya yang sempurna 30 juz. ${ }^{19}$

Lanre Said punya metode dalam menjaga hafalannya, selain memang sewaktu belajar di MAI Sengkang di bawah asuhan Al-Bugisi sudah selesai hafalannya 30 Juz dengan sempurna, juga metode menghafalnya yang unik, yakni mengulang-ulang hafalan dari juz 1 hingga juz 30 sebanyak 40 kali tanpa henti, dan tidak boleh menyentuh AlQur'an, inilah yang disebut dengan metode (afala' patappulo) yang dimulai dengan membaca 40 kali (baca patappulo). Setelah itu, dia cukup mengulang hafalan di bulan Ramadhan dengan K.H.atam sekali dalam sehari, selanjutnya untuk terus mengingatingat hafalan, maka Lanre Said di mana pun berada selalu ada yang menjadi

19 Andi Siti Nurhasanah, wawancara di Palattae, 08/08/2018 
muridnya, dengan artian ada saja yang datang menyetor hafalan kepadanya. Kalau murid tidak ada, maka istri yang menjadi muridnya, karena itulah istrinya yang bernama Andi Siti Nurhasanah dimana selama melaksanakan perjalanan hingga ke luar Sulawesi setia dan selalu menemaninya juga hafal 30 juz Al-Qur'an dengan sempurna, termasuk tafsir dan terjemahannya. ${ }^{20}$

Dari sisi kepribadian, tidak diragukan lagi bahwa K.H. Lanre adalah ulama yang memiliki ampe-ampe madeceng adab yang mulia. Misalnya dalam hal sedekah, sejak masih sekolah di MAI Sengkang, dia tidak pernah makan tanpa berjamaah. Karena saat itu setiap santri masing-masing mengurus makanannya sendiri-sendiri, masingmasing bawa alat masak dan logistik untuk dimasak. Maka tentu saja antara satu santri dengan lainnya punya menu yang berbeda, disesuikan dengan bekal yang tersedia. Lanre Said, sejak saat itu, tidak pernah makan tanpa ditemani oleh rekan-rekannya dan kebiasaan itu terus ia lakukan hingga menjelang tutup usia. Bahkan seorang tamu, yang datang ke Pondok Pesantren Darul Huffadh Tuju-Tuju pernah menangis menyaksikan seorang ulama besar, namanya begitu dikenal, tetap ketika makan, beliau makan bersama dengan para santrinya. Apa yang ingin diperlihatkan kepada para santrinya bahwa apa yang Lanre Said makan, itu pula yang dimakan oleh para santri. Dan sering terjadi hal yang sungguh menggugah bahwa Lanre Said terpaksa menunda untuk makan karena hidangan yang ada di depannya dialihkan kepada santri atau tamu yang

20 Andi Siti Nurhasanah, wawancara di Palattae, 08/08/2018 baru tiba. Hal ini terjadi karena takaran bahan baku yang dimasak sesuai dengan jumlah guru dan santri, lalu tanpa perkiraan tetiba ada tamu atau santri baru, maka terpaksa harus menunggu untuk dimasakkan kembali. $^{21}$

\section{Pesan dan Wasiat}

Sebagai ulama yang memiliki mata batin yang tajam (bashirab) dengan arti mampu membaca tanda-tanda alam serta fenomena zaman, maka pasti ada wasiat yang disampaikan kepada siapa saja yang inginkan kebenaran, atau hidup dalam jalan agama dan dakwah. Pesan dan wasiat tersebut kadangkadang tidak begitu penting ketika pemberi pesan masih hidup bersama orang yang diberi pesan, namun jika salah satunya telah tiada barulah pesan dan wasiat itu terasa penuh makna. Berikut pesan dan wasiat K.H. Lanre Said sebagaimana ditulis Palimai (2010: 133-143).

Pertama. Kalau kalian ingin mengerjakan suatu pekerjaan pertamatama perbaiki niat. Kedua. Bila ada rencana hendak mengerjakan suatu pekerjaan yang berat sebaiknya dirikan dahulu shalat istiK.H.arah atau shalat hajat dua rakaat, lalu berdo'a minta petunjuk semoga Allah memberikan kemudahan atas rencanaNya; Ketiga. Sabar dan bertahanlah menghadapi segala tantangan dan cobaan, karena hal itu mutlak adanya; Keempat. Biasakan berkata benar dan jangan suka berdusta sekalipun bermain-main; Kelima. Bila kalian ingin memperluas dan memperdalam ilmu, lepaskanlah sifat kepanatikan, jangan fanatik guru,

21 Andi Siti Nurhasanah, wawancara di Palattae, 08/08/2018 
ulama tertentu, ataupun fanatik mazhab; Keenam. Pelajarilah Ilmu yang dua belas (12) karena itu dapat memudahkan untuk mengetahui isi tujuan al Qur'an dan Hadis serta kitabkitab lainnya. Yang dimaksud oleh Lanre Said dengan ilmu duabelas adalah sebagai berikut: ilmu nahwu, sharaf, fighi, tafsir, tauhid, hadits, musthalah hadits, mantiq, ma'ani, bayan, badi', dan ushul al fiqhi. (Mahmud Yunus, 1996: 53-54). Ketujuh. Pelajarilah sejarah hukum dan sejarah lainnya yang ada kaitannya dengan agama Islam; Kedelapan. Usahakan memiliki dan memperbanyak kitabkitab, terutama kitab para Imam mazhab; Kesembilan. Tetaplah berusaha mengetahui dan mengmalkan tuntunan al Qur'an dan Hadis Shohih yang telah dicontohkan atau digariskan oleh Rasulullah dan para sahabat serta para ahlussunnah dari segi aqidah dan ibadah; Kesepuluh. Ketahuilah bahwa kekuatan pondok ini ada tiga hal yang ada pada diri saya, tidak melakukan dosa besar, tidak mengutamakan diri dan keluarga melebihi kepentingan pondok, dan tidak memungut bayaran kepada para santri. Artinya, bagi para santri yang hendak mengikuti jejaknya dalam membangun dan mengelola lembaga pendidikan, atau untuk sanak familinya yang kini melanjutkan estafet kepemimpinannya, jika hendak sukses seperti Lanre Said maka hanya ada satu jalan, ikuti nasihat dan petuahnya tersebut.

\section{PENUTUP}

Telah menjadi bukti nyata bahwa kiprah ulama dalam mencerdaskan kehidupan bangsa adalah kongkrit adanya. Kedudukan merekan seperti permata yang berharga, K.H. Lanre
Said adalah contoh, sebagi ulama yang telah mencurahkan segenap usianya untuk belajar dan mengajar, kapan pun dan di mana pun. Sejak zaman DI/TII hingga aK.H.ir hayatnya di era reformasi. Kerja nyatanya dalam berdakwah masih terlihat jelas hingga detik ini, mulai dari kiprah muridmurid yang telah dididik hingga jadi tokoh nasional, buku-buku panduan dalam beribadah yang ia tulis, hingga Pondok Pesantren Darul Huffadh yang berlokasi di Tuju-Tuju Kajuara, Bone Sulawesi Selatan hingga saat ini menjadi salah satu lembaga pendidikan di Indonesia, pilihan bagi umat untuk mengirim generasi ke sana, mereka dapat belajar dengan biaya yang minim dengan kualitas yang mumpuni. Selain itu, K.H. Lanre Said terus dan akan terus jadi buah bibir yang manis atas jasa-jasa baiknya di tengah masyarakat, Khususnya masyarakat Tuju-Tuju Bone yang menjadikan daerah tersebut jadi tujuan menuntut ilmu yang dulunya tidak dikenal. Dan tak kalah pentingnya adalah, sosoknya yang layak jadi panutan, K.H.usunya bagi para penuntut ilmu agar semangat menguasai ilmu-ilmu yang harus dikuasi untuk menjadi seorang ulama mujtahid, menjadi ulama adalah sebuah proses panjang, tidak boleh instan. Ada pun pesan dan petuah-petuah Lanre Said ibarat mutiara yang nilainya tidak pernah surut. Pesan-pesan tersebut adalah bekal bagi siapa saja yang menginginkan kebenaran tanpa kenal seting ruang dan waktu. Di tengah maraknya fitnah, orang jahil begitu muda berfatwa, orang alim kalah popular dengan golongan jahil, dan kerap lahir pernyataan yang membingungkan dari tokoh yang tidak jelas latar belakang keilmuannya, selain itu adalah maraknya bohong di media 
sosial yang bukan saja sekedar bercanda tapi memang sengaja menyebarkan kebohongan. Pesan-pesan dan wasiat Lanre Said layak jadi pegangan bagi siapa pun.

\section{UCAPAN TERIMA KASIH}

Pada bagian akhir dari tulisan ini, penulis mengucapkan terima kasih kepada para narasumber atas kerjasamanya dalam memberikan informasi akurat terkait dengan berbagai sisi kehidupan K.H. Lanre Said semasa hidupnya. Mereka adalah: Anregurutta Hj Siti Nurhasanah, Dr. Muttaqien Said, MA, Andi MuK.H.tar Longi, S.Pd, Muhammad Nasir, Sp.D., Azhar Azis. S.S, Kamaruddin, S.Pd.I. Ucapan terima kasih juga disampaikan kepada rekan peneliti di Litbang Kemenag Sulawesi Selatan, Muhammmad Subair yang mendorong peneliti agar meneliti para ulama Bugis dari Bone, juga terima kasih banyak kepada reviewer dan pembaca ahli Jurnal PENAMAS yang telah memberikan masukan, catatan penting dan pembenahan dalam berbagai aspek untuk penyempurnaan artikel ini, peneliti merasa sangat beruntung mendapatkan catatan, teguran dan perbaikan, dari para reviewer. Semoga artikel ini dapat memberi manfaat dan menambah wawasan bagi pembaca, terutama pemerhati kajian pendidikan dan keulamaan di tanah Bugis.

\section{DAFTAR PUSTAKA}

Ahmad, Abd. Kadir. 2008. Ulama Bugis, Makassar: Balai Penelitian dan Pengembangan Agama.

Al-Attas, S.M.N., Islam and Secularism, diterjemahkan oleh K.H.alif Muammar dengan judul, Islam dan Sekularisme, Bandung: PIMPIN, 2011.

Albone, Abd. Aziz. 1986. Lembaga Pendidikan Islam di Sulawesi Selatan, Studi Kasus di Perguruan As'adiah Sengkang, Jakarta: ZYUS.

Arif, Syamsuddin. 2007. Jaringan Pesantren di Sulawesi Selatan (19282005). Disertasi UIN Syarif Hidayatullah Jakarta.

Arsyad, Azhar, dkk. 2013. Ke-DDI-an, Sejarah dan Pandangan, atas Isu-Isu Kontemporer, Yogyakarta. LkiS.

As'ad, Muhammad. 2011. Cappa Kallanna AG.H. Daud Ismail, dalam Muh. As'ad dkk. Buah Pena Sang Ulama, Makassar: Balai Penelitian dan Pengembangan Agama Makassar.

------. 2015. K.H.. Abdurrahman Pakkanna: Ulama Pemikir Praktis dan Pekerja Profesional, dalam Jurnal Al-Qalam, Volume 22 Nomor 2, Desember 2016.

Asdar, Muhammad. 2012. Sistem Pendidikan Pondok Pesantren Darul Huffadh. Tesis magister di Universitas Muslim Indonesia.

Awwas, Irfan S. 2015. Kesaksian Pelaku Sejarah Darul Islam (DI/TII). Jogjakarta: Darul Uswah.

Azra, Azyumardi, 1994. Jaringan Ulama Timur Tengab dan Kepulauan Nusantara Abda XVII dan XVIII. Bandung: Mizan

Daud, Wan Mohd Nor Wan. 2003. The Educational Philosophy and Practice of Syed Muhammad Naquib AlAttas, diterjemahkan oleh Hamid Fami Zarkasyi, et al dengan judul, Filsafat dan Praktik. Pendidikan Islam Syed M. Naquib Al-Attas, Bandung: Mizan.

Dijk, C. Van. 1993. Rebellion under the banner of Islam (The DarulIslam in 
Indonesia), edisi Indonesia, Darul Islam: Sebuab Pemberontakan, Jakarta: Penerbit Majalah Tempo.

Getteng, Abd. Rahman. 2005. Pendidikan Islam di Sulawesi Selatan: Tinjauan Historis dari Tradisional Hingga Modern, Jakarta: Penerbit Graha Guru.

Gonggong, Anhar. 2004. Abdul Kabhar Murakekar, dari Patriot hingga Pemberontak. Jakarta: Ombak.

Hamka, Zainuddin. 2009. Corak Pemikiran Keagamaan Gurutt $H$. Mubammad As'ad Al-Bugisi, Jakarta: Dep. Agama RI, Puslitbang Lektur Keagamaan.

Horikoshi, Hiroko. 1987. Kiyai dan Perubahan Sosial, Jakarta: LP3M.

https://id.wikipedia.org/wiki/Kabupa ten_Bone.

http://www.ilhamkadir.com/2013/02 /gurutta-anreguru-panrita.html.

https://id.wikipedia.org/wiki/Anregu rutta

https://www.academia.edu/37618597 /Gurutta_Anreguru_Panrita

Ibn K.H.aldun, Abd Rahman bin Muhammad. 2010. AlMuqaddimah, tahqid,Majdi Fathi al-Sayyed, Kairo: Dar alTaufíqiyah li al-Turats.

Kadir, Ilham. 2012. Islamisasi Sulawesi Selatan: Peran Ulama dan RajaRaja, dalam Jurnal Pemikiran dan Peradaban Islam "ISLAMLA", Vol. VII, No. 2. 2012.

, 2017. Kaderisasi Ulama: Kiprah K.H.. Muhammad As'ad, Jurnal Pemikiran dan Peradaban Islam "TSLAMLA", Vol. XI, No. 1. Februari 2017.

2013. Konsep Pemikiran
Pendidikan Syed Mubammad
Naquib Al-Attas. Tesis Magister

Universitas Muslim Indonesia, Makassar.

Ilham, 2018. Al-Bugisi dan Pendidikan Kader Ulama. Dalam Jurnal Penelitian Agama dan Masyarakat "PENAMAS". Velume 31, No. 2. Juli-Desember 2018. 2017. Konsep Pendidikan Kader Ulama Anregurutta Mubammad As'ad Al-Bugisi (1907-1952). Disertasi di Sekolah Pascasarjana UIKA Bogor.

Katu, Mas Alim. 2007. AGH. Muhammad As'ad, dalam $\mathrm{H}$. Muhammad Ruslan dan Waspada Santing (Ed.), Ulama Sulawesi Selatan; Biografi Pendidikan dan Dakwah, Makassar: Komisi Informasi dan Komunikasi MUI Sulsel.

Matulada. 1988. Sejarah Kebudayaan dan Masyarakat Sulawesi Selatan, Makassar: Unhas Press.

Said, Lanre. 1995. Adz-Drikra, 1,2,3,4,5A-5E. Tuju-Tuju: Lembaga Pengajian Majelisul Qurra' Wal Huffazh.

Palimai, Ilham Kadir. 2010. Jejak Dakwah K.H. Lanre Said: Ulama Pejuang dari DI/TII hingga Era Reformasi, Yogyakarta: Aynat Publishing.

Rasmin, Rasmin, 2018. Pendidikan Islam dalam Perspektif Ulama Bugis K.H. Lanre Said, dalam Jurnal Pendidikan Islam "Ta'dibuna", Vol. 7. No. 1, April 2018.

Tim Penulis Darul Huffadh. 2015. Etta, Meniti di Dalam Cahaya: Kisah Hidup Anre Gurutta H. Lanre Said, Pendiri dan Pimpinan PondokPesantren Darul Huffadh Tијu-Tијu, Sidoarjo: Daffa Publishing. 
NUKHBATUL 'ULUM : Jurnal Bidang Kajian Islam

"IURNAL

Vol. 5, No. 2 (2019) : Hal. 125-144

Website: https://journal.stiba.ac.id

ISSN : 2685-7537 (online); 2338-5251 (Printed)

Yunus, Mahmud. 1996. Sejarah

Pendidikan Islam di Indonesia,

Jakarta: Hidakarya Agung. 